\title{
Experience and levels of satisfaction with the levonorgestrel-releasing intrauterine system in China: a prospective multicenter survey
}

\author{
Shuping Zhao' \\ Jihong Deng ${ }^{2}$ \\ Yan Wang ${ }^{3}$ \\ Shiliang $\mathrm{Bi}^{4}$ \\ Xiaoye Wang ${ }^{5}$ \\ Wen Qin ${ }^{6}$ \\ Zirong Huang ${ }^{7}$ \\ $\mathrm{Li} \mathrm{Li}{ }^{8}$ \\ Xin $\mathrm{Mi}^{9}$ \\ Liping Han ${ }^{10}$ \\ Qing Chang"I \\ Jian $\mathrm{Li}^{12}$
}

'The Affiliated Hospital of the Medical College Qingdao University, Qingdao, ${ }^{2}$ Kunming Maternal and Child Health Hospital, Kunming, ${ }^{3}$ Hubei Maternity and Child Health Hospital, Wuhan, ${ }^{4}$ West China Second University Hospital, Sichuan University, Chengdu, ${ }^{5}$ Peking University Third Hospital, Beijing, ${ }^{6}$ Changzhou Maternity and Child Health Hospital, Affiliated to Nanjing Medical University, Jiangsu,

${ }^{7}$ The Affiliated Women's Hospital of Fudan University, Shanghai,

${ }^{8}$ Guangzhou Women and Children's Medical Center, Guangzhou, ${ }^{9}$ Maternity and Child Health Care Hospital, Shunyi District, Beijing, ${ }^{10}$ The First Affiliated Hospital of Zhengzhou University, Zhengzhou City, Henan, "Southwest Hospital, Chongqing City, Chongqing, ${ }^{12}$ Beijing Obstetrics and Gynecology Hospital, Capital Medical University, Beijing, People's Republic of China

Correspondence: Jian Li Beijing Obstetrics and Gynecology Hospital, Capital Medical University, 25I Yaojia Yuan Road, Beijing, People's Republic of China

$\mathrm{Tel}+861052275418$

Fax +86 I0 52275418

Email lijian02@hotmail.com
This article was published in the following Dove Press journal:

Patient Preference and Adherence

23 October 2014

Number of times this article has been viewed

Background: Although surveys conducted in Western countries have shown that the levonorgestrel-releasing intrauterine system (LNG-IUS; Mirena ${ }^{\circledR}$ ) is well accepted by European women, its acceptance by Chinese women is not yet clearly known. The purpose of this study was to analyze the experiences and levels of satisfaction with Mirena among Chinese women living in 12 different cities.

Methods: In total, 1,021 women who attended 21 medical centers for insertion of Mirena were invited to complete a questionnaire regarding their contraceptive decision at baseline (preinsertion), and two further questionnaires on their experience and satisfaction with Mirena at 3-6 months and 1 year after insertion.

Results: At baseline, $36 \%$ of women self-reported heavy or very heavy menstrual bleeding, while $41 \%$ reported normal bleeding. The majority of women (98\%) were satisfied with the preinsertion counseling, during which contraceptive reliability was identified as the most important reason for considering Mirena. Continuation rates for Mirena were 99\% at 3-6 months and 93\% at 12 months after insertion, and most women ( $92 \%$ and 93\%, respectively) had less bleeding at these times. The percentage of women who rated Mirena as better than their previous contraceptive method was $63 \%$. Overall, around $90 \%$ of respondents were very satisfied or rather satisfied with Mirena, and $64 \%$ stated that they would recommend it to their friends.

Conclusion: These data suggest that continuation and satisfaction rates with Mirena were very high, and that the device is well accepted by Chinese women.

Keywords: levonorgestrel-releasing intrauterine system, intrauterine device, contraception, user satisfaction

\section{Introduction}

The levonorgestrel-releasing intrauterine system (LNG-IUS; Mirena ${ }^{\circledR}$; Bayer Healthcare Pharmaceuticals, Whippany, NJ, USA) is a drug delivery option that has proven efficacy in providing contraception and improving heavy menstrual bleeding. In addition, numerous studies have indicated that Mirena also has reliable safety and cost-effectiveness. ${ }^{1,2}$ In a review of the contraceptive efficacy of intrauterine devices, a cumulative pregnancy rate of less than $0.5 \%$ at 5 years after insertion of Mirena was reported, and the rate was less than $2 \%$ at 5 years whatever the type of intrauterine device was used. ${ }^{3}$ A cost-utility analysis of various contraceptive methods conducted in 2004 found that the 2-year health gains associated with LNG-IUS (0.146 qualityadjusted life years) was one of the highest among the reversible methods of contraception analyzed. ${ }^{4}$

In 2009, an international survey conducted in 18 countries of Europe and the Near East reported that $95 \%$ of new users and $99 \%$ of users of their second Mirena were 
satisfied with the device, and that it provided considerable benefits beyond contraception alone (eg, in improving bleeding problems). ${ }^{5}$ A 3 -year follow-up study in Austria also showed that Mirena was well accepted as a contraceptive method, with no negative impact on sex life, and was a suitable method for long-term contraception. ${ }^{6}$ Although these studies taken together indicate that Mirena has been well accepted by European women, its acceptance by Chinese women is not yet clearly known. This survey analyzed the experience and levels of satisfaction among Chinese women using Mirena.

\section{Materials and methods}

This prospective multicenter survey was conducted at 21 centers in 12 Chinese cities (Beijing, Qingdao, Tianjin, Shenyang, Zhengzhou, Shanghai, Nanjing, Guangzhou, Chongqing, Chengdu, Wuhan, and Kunming) during the period June 2012 to September 2013. The selection of centers for the study was based on health care expenditures (in Chinese Yuan [CNY]) in 2006: > CNY 5 million for centers in Beijing, Shanghai, Guangzhou, which were defined as city group 1; CNY 2.5-5 million in Chengdu, Wuhan, Nanjing, Tianjin, Shenyang, and Chongqing, which were defined as city group 2; and < CNY 2.5 million in Changzhou, Foshan, Kunming, Zhengzhou, and Qingdao, which were defined as city group 3. This was done to include a broad range of representative centers of varying socioeconomic status. Approval for the study was secured from the ethical committee of Beijing Capital University.

All women who agreed to participate in the survey and signed an informed consent form to do so were asked to complete a questionnaire on their contraceptive choices and their demographic information at baseline. The baseline questionnaire contained items about their opinions and experiences with previous contraception methods, preinsertion counseling and the reason for fitting the Mirena, and on their age, family plans, and current bleeding patterns. The comprehensive information about Mirena that was provided to investigators for the preinsertion counseling was the same at all study centers. After insertion of Mirena, the participants were asked to complete two follow-up visit questionnaires on their experiences and levels of satisfaction at 3-6 months and 1 year after insertion. The two follow-up visit questionnaires contained items about their continuing usage of Mirena, the adequacy of the information they had received, their current bleeding patterns, and their experience, satisfaction, and recommendations regarding Mirena.

\section{Data analysis}

All questionnaires were completed by the participants at the various study centers and were returned to the clinicians, who then forwarded them to Shanghai Synergy-Strategy Marketing Research \& Consulting Ltd for further analysis. No formal hypotheses were tested and only relative percentages were calculated for overall responses by age groups and city groups.

\section{Results}

A total of 1,021 women were invited to participate in the survey at 21 medical centers across the People's Republic of China. Fifty-five women (5.4\%) did not complete the first follow-up visit at 3-6 months and 121 (11.9\%) did not complete the second visit at 1 year, the reasons for which were unknown, but most were considered lost to follow-up after two or three phone calls during the follow-up period. Among nulliparous women $(\mathrm{n}=77)$, the dropout rates were similar to those of the whole group (3.8\% and 9\%, respectively).

Thus, 966 women remained in the study and completed the follow-up questionnaire at the first follow-up visit (which was conducted at a mean of 3.2 months after insertion of Mirena), and 900 remained in the study and completed the follow-up questionnaire at the second follow-up visit at 1 year after insertion. At these visits, 99\% (956/966) and 93\% (837/900) of respondents, respectively, were using Mirena continuously.

\section{Profile of Mirena users}

The baseline characteristics of the Mirena users are listed in Table 1. The majority (59\%) of the women were aged $30-40$ years, and most (76\%) had only one child, with only $8 \%$ being nulliparous. Figure 1, which shows the respondent's recall of the standardized information about Mirena that was provided during the preinsertion counseling, indicates that more than $50 \%$ recalled the information about its contraceptive effectiveness, the possibility of irregular bleeding during the first months after insertion, and the gradual reduction of bleeding and possibility of missed periods that could be expected. However, only $26 \%$ could recall receiving the standardized information about the possibility of hormonal side effects, and only $38 \%$ could recall receiving the information given about possible expulsion of the device. Nevertheless, most women (98\%) were either very satisfied or rather satisfied with the preinsertion counseling. Information about its contraceptive reliability was the most important reason stated for choosing Mirena, followed by its good tolerability and convenience. 
Table I Baseline characteristics of the respondents $(n=I, 02 I)$

\begin{tabular}{lc}
\hline Characteristic & $\%$ \\
\hline Age, years & 16 \\
$<30$ & 59 \\
$30-40$ & 25 \\
$>40$ & \\
City group ${ }^{\mathrm{a}}$ & 34 \\
I & 34 \\
2 & 32 \\
3 & \\
Number of children per respondent & 8 \\
No children & 76 \\
One child & 16 \\
More than one child & \\
Respondents planning on having children & $1 \mathrm{I}$ \\
Yes & 76 \\
No & 13 \\
Do not know & \\
Previous contraceptive methods & 83 \\
Condoms & 32 \\
Oral contraceptives & 23 \\
Copper IUD & 23 \\
Natural methods & 3 \\
Mirena & \\
Others & \\
Mirena implantation time & 10 \\
After/during normal menstrual period & 32 \\
After abortion & 4 \\
After giving birth & \\
Other & 56 \\
\hline
\end{tabular}

Notes: ${ }^{2}$ City group I, health care expenditure in $2006>$ CNY 5 million; city group 2, health care expenditure in 2006 CNY 2.5-5 million; city group 3, health care expenditure in $2006<$ CNY 2.5 million. ${ }^{b}$ Chemical methods, female/male sterilization, and injections/ implants. Mirena ${ }^{\circledR}$ (Bayer Healthcare Pharmaceuticals, Whippany, NJ, USA).

Abbreviations: IUD, intrauterine device; CNY, Chinese Yuan.

At baseline, $36 \%$ of women self-reported heavy or very heavy menstrual bleeding, $41 \%$ reported normal bleeding, and the remainder had either light or no bleeding. As shown in Figure 2, 55\% of respondents had Mirena fitted for contraception purposes. In the remainder, the reason for inserting Mirena was to treat heavy menstrual bleeding or other gynecological conditions, or other reasons. Interestingly, the proportion of women in whom Mirena was fitted for noncontraceptive purposes increased with age and was much higher in city group 3 than in the other city groups. In the majority of women, the timing of Mirena insertion was after or during a normal menstrual period (56\%), followed by after an abortion (32\%), and to a lesser degree, after giving birth or for other reasons (12\%).

Table 1 also shows the contraceptive methods previously used by respondents, which included condoms $(83 \%)$, oral contraceptives (32\%), copper intrauterine devices (23\%), natural methods (23\%), Mirena (3\%), and other methods, such as chemical methods, female/male sterilization, and injection/implants (4\%).

\section{Acceptability of Mirena at follow-up visits}

Most women who completed the survey were still using Mirena at the follow-up visits. The continuation rates of Mirena were $99 \%$ at 3-6 months and $93 \%$ at 12 months. Furthermore, $92 \%$ and $93 \%$ of the respondents, respectively, experienced less bleeding at these visits, which was not related to their baseline bleeding profile. Among nulliparous women $(n=77)$, the continuation rate was $90 \%$ at 12 months after insertion of Mirena.

In comparison with their previously used contraceptive methods, $63 \%$ of women thought that Mirena was better than their previous method, while $10 \%$ rated Mirena as equally good, and $3 \%$ rated it as worse than the previous method.

The data in Figure 3 indicate that around $90 \%$ of respondents were either very or rather satisfied with Mirena, and only $1 \%-2 \%$ were very dissatisfied. Although the reasons for fitting Mirena were different, the levels of satisfaction in the different age groups were similar. In the different city groups, city groups 2 and 3 had higher percentages of respondents who rated Mirena as very satisfactory in comparison with city group 1 ( $44 \%$ and $43 \%$ versus $20 \%$, respectively). Among the $24 \%$ of users who had never used contraception previously (including the $23 \%$ who used a natural method), $87 \%$ indicated that they were satisfied with Mirena. In nulliparous women $(n=77)$, the satisfaction rate was $92 \%$ at the first follow-up visit and $85 \%$ at the second.

After using Mirena, most women agreed with the preinsertion counseling that they had received. Interestingly, the levels of agreement regarding information on product attributes such as convenience, contraceptive reliability, therapeutic benefits with regard to bleeding, rapid recovery of fertility after removal, good tolerability, the low dose of hormones received, and good menstrual cycle control were higher at the second follow-up visit than at the first (Figure 4A). More respondents in city group 3 agreed with the information they had been given on attributes such as convenience, therapeutic benefits with regard to bleeding, and contraceptive reliability at the second follow-up visit than respondents in the other city groups (Figure 4B), and the levels of agreement with the first two of these attributes in city group 3 were similar to those at the first follow-up visit. Among respondents over 40 years of age, $81 \%$ agreed with the information they had been given on the therapeutic benefits with regard to bleeding (Figure 4C), which reflected the most frequent reason for inserting Mirena in this age group. 


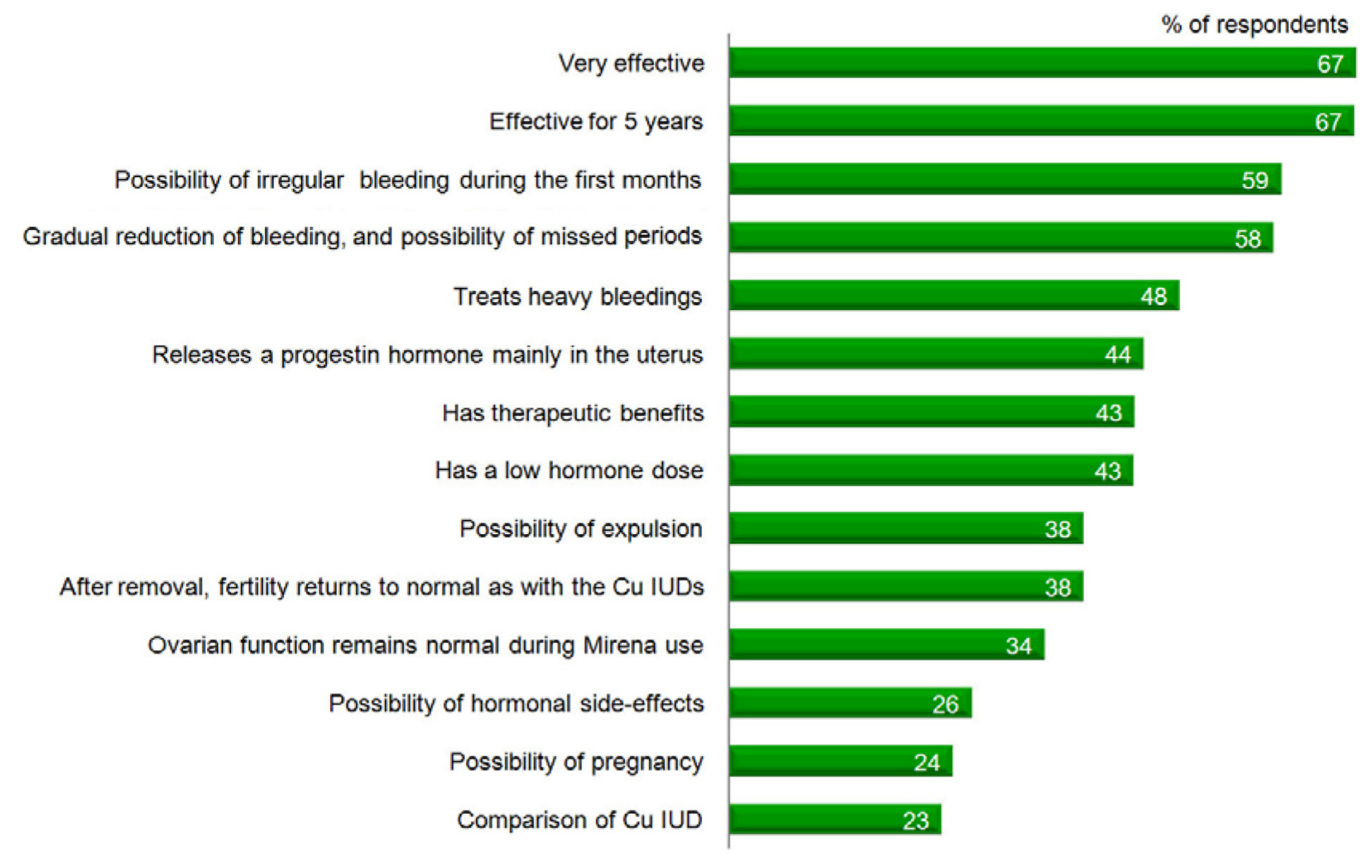

Figure I Patients' recall of the standardized information on Mirena ${ }^{\circledR}$ (Bayer Healthcare Pharmaceuticals, Whippany, NJ, USA) they had received during preinsertion counseling.

Abbreviation: IUD, intrauterine device; $\mathrm{Cu}$, copper.

\section{Recommendations for Mirena use}

The percentage of women who stated that they would recommend Mirena to their friends was $71 \%$ at the first follow-up visit and $64 \%$ at the second follow-up visit (Figure 5). More respondents in city group 3 and in the age group $>40$ years at the second follow-up visit stated that they would recommend Mirena to their friends than respondents in the other subgroups (Figure 5).

\section{Discussion}

This survey is the first prospective, multicenter study of Mirena usage to be conducted in the People's Republic of China. As in European surveys, ${ }^{5,6}$ it was found that Mirena is well accepted by Chinese women. Among the women who participated, $93 \%$ were found to be still using Mirena at 12 months after its insertion, which is similar to the findings of a large Finnish study ${ }^{7}$ but slightly lower than that of an

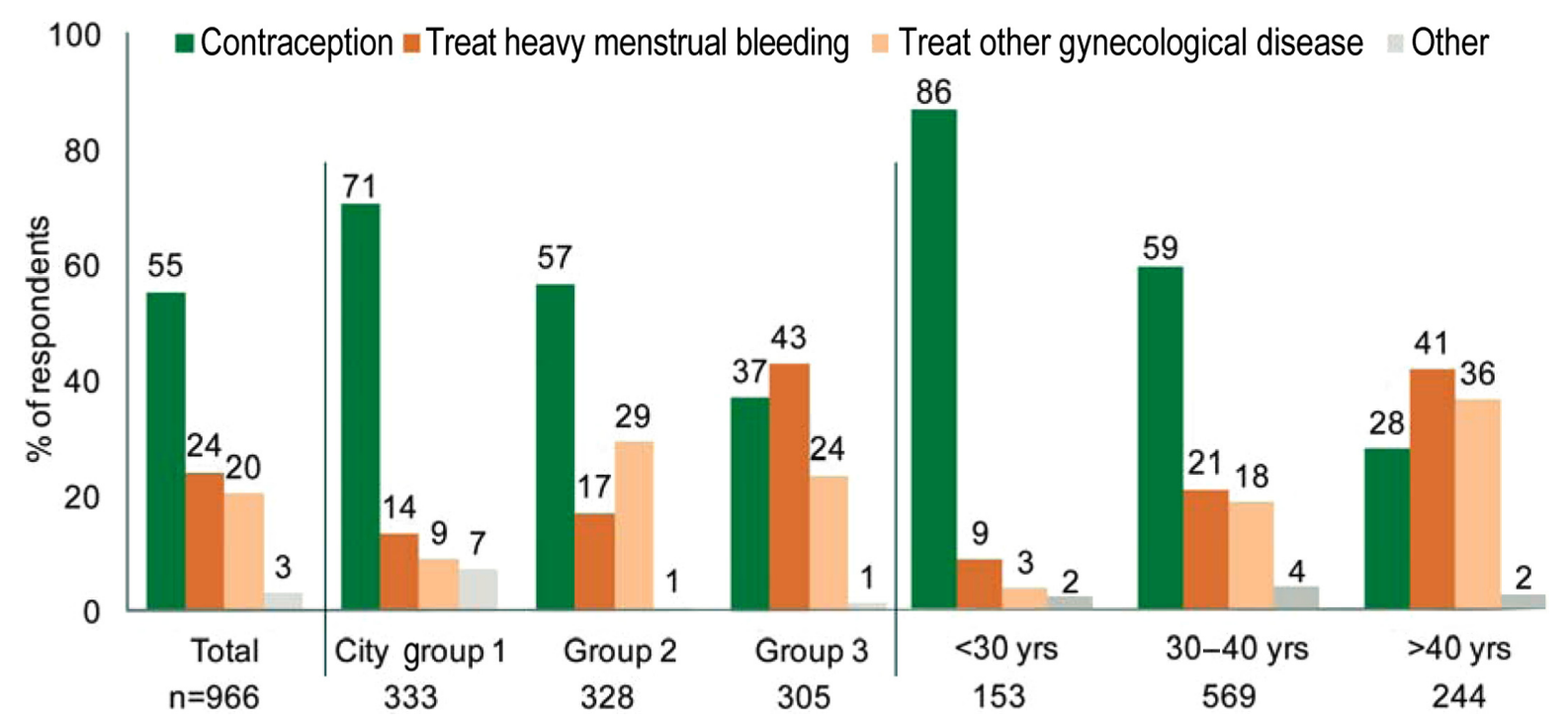

Figure 2 Reasons for inserting Mirena ${ }^{\circledR}$ (Bayer Healthcare Pharmaceuticals, Whippany, NJ, USA). Abbreviation: yrs, years. 


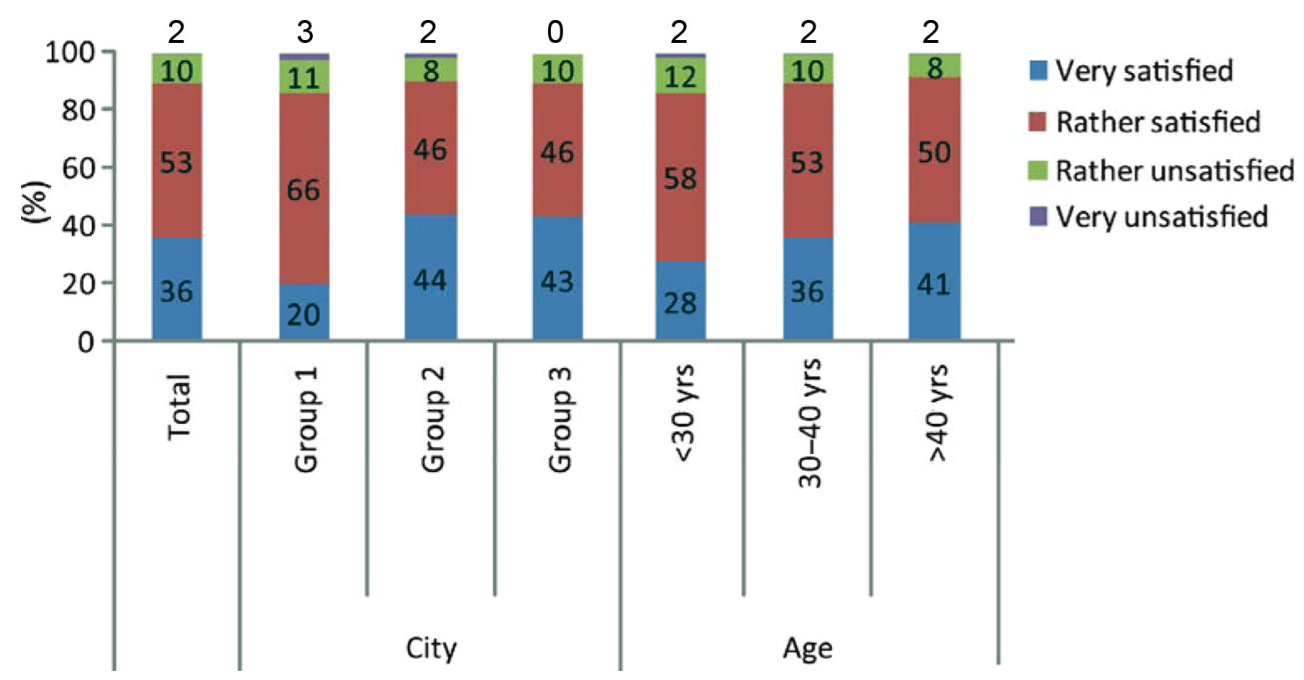

Figure 3 Rates of satisfaction with Mirena ${ }^{\circledR}$ (Bayer Healthcare Pharmaceuticals, Whippany, NJ, USA) at the second follow-up visit.

Austrian survey $(95.8 \%, 158 / 165) .{ }^{6}$ The high continuation rate of Mirena in our study was probably due to the high level of satisfaction with its use and the high level of agreement with the information on its attributes offered at the preinsertion counseling. In the nulliparous group ( $8 \%$ of the total number who participated), the continuation rate at 12 months after insertion of Mirena was also high (90\%). Other studies have reported that continuation rates in nulliparous women are slightly lower $(76 \%-80 \%),{ }^{8,9}$ but that its acceptability is high in comparison with parous users or nulliparous users of combined oral contraceptives. ${ }^{8,10}$ Our findings regarding its acceptability by nulliparous women were similar, as the satisfaction rate in this group was $92 \%$ at the first follow-up visit and $85 \%$ at the second.

Before insertion of Mirena, about one third (37\%) of the respondents in this survey had normal menstrual bleeding and another one third (34\%) had heavy bleeding. A decrease in bleeding was experienced by $92 \%$ of Mirena users who had either heavy or light bleeding at baseline. Mirena, as an intrauterine progestin-releasing system, makes the endometrium unresponsive to circulating estradiol, irrespective of ovarian function, and through this action, endometrial suppression leads to less menstrual blood loss and even, temporarily, to no bleeding. ${ }^{11}$ A change in bleeding pattern was one of the most important aspects of the preinsertion counseling offered, and more attention to this attribute is being given by Chinese clinicians. The majority of respondents in our survey (93\%) were satisfied with Mirena at the first follow-up visit after its insertion. Although there was a slight decrease in the level of satisfaction (89\%) at the second follow-up visit, the satisfaction levels were comparable with those reported in a previous international survey $(95 \%) .^{5}$
Almost two thirds of the respondents in our survey agreed with the information offered on the attributes of Mirena and would recommend it to their friends, although there was a slight decrease in the proportion who would recommend it at the second follow-up visit, which was probably related to the slightly lower level of satisfaction at this time. The high levels of satisfaction that we observed were probably due not only to the good preinsertion counseling that was offered (and the comprehensive information about Mirena that was provided), but also to the high levels of agreement with the counseling information noted at follow-up visits.

Interestingly, it was found that the city group 3 and older age ( $>40$ years) subgroups were more likely to recommend Mirena to their friends. In both of these subgroups, more women were fitted with Mirena for therapeutic reasons than for contraception, and agreed more with the information offered on the therapeutic benefit with regard to bleeding. Consequently, this could partly explain the higher recommendation rates recorded for these subgroups.

Although Mirena was found to be well accepted by Chinese women in this survey, there are some limitations that need to be considered. First, the sample size of the survey was not very large. Although more than 1,000 women were recruited for the study, over $50 \%$ of the study centers recruited fewer than 30 women. Second, the participants were all city-based and none were rural-based, and the results can be considered only partly representative of the current population of Mirena users in the People's Republic of China. Third, the study had a maximum follow-up of only 1 year, and whether the continuation rates will decrease after this time could not be quantified. Finally, it is possible that some patients may have missed receiving the standardized 


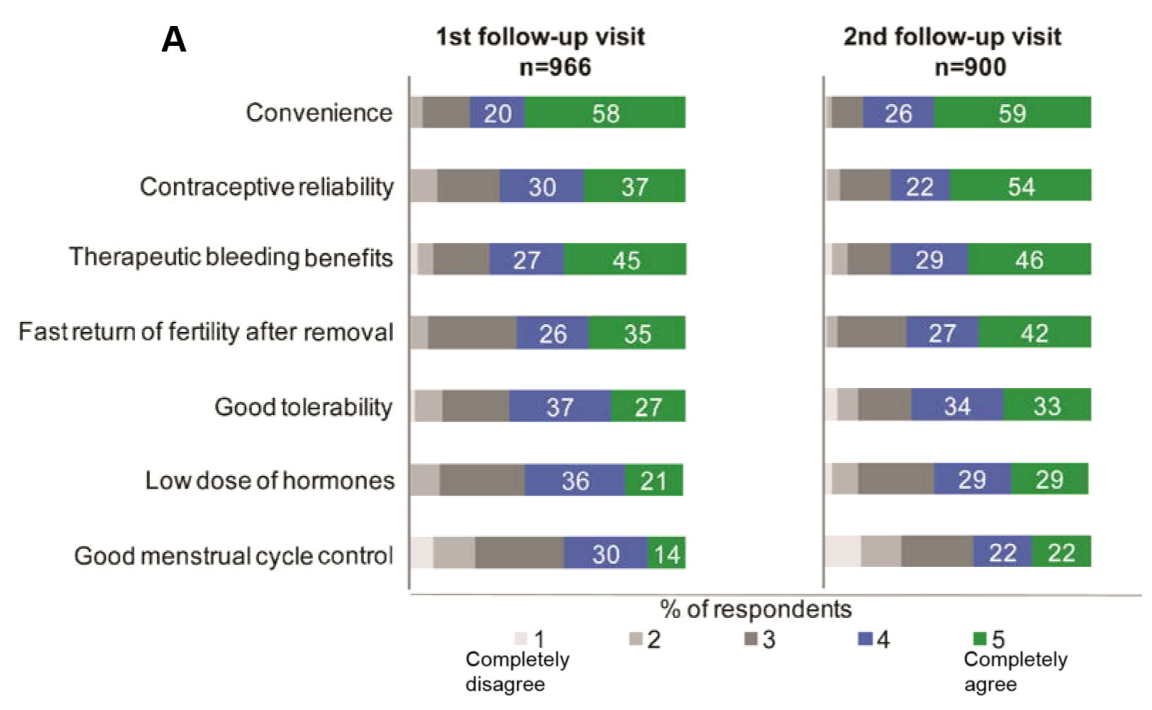

B
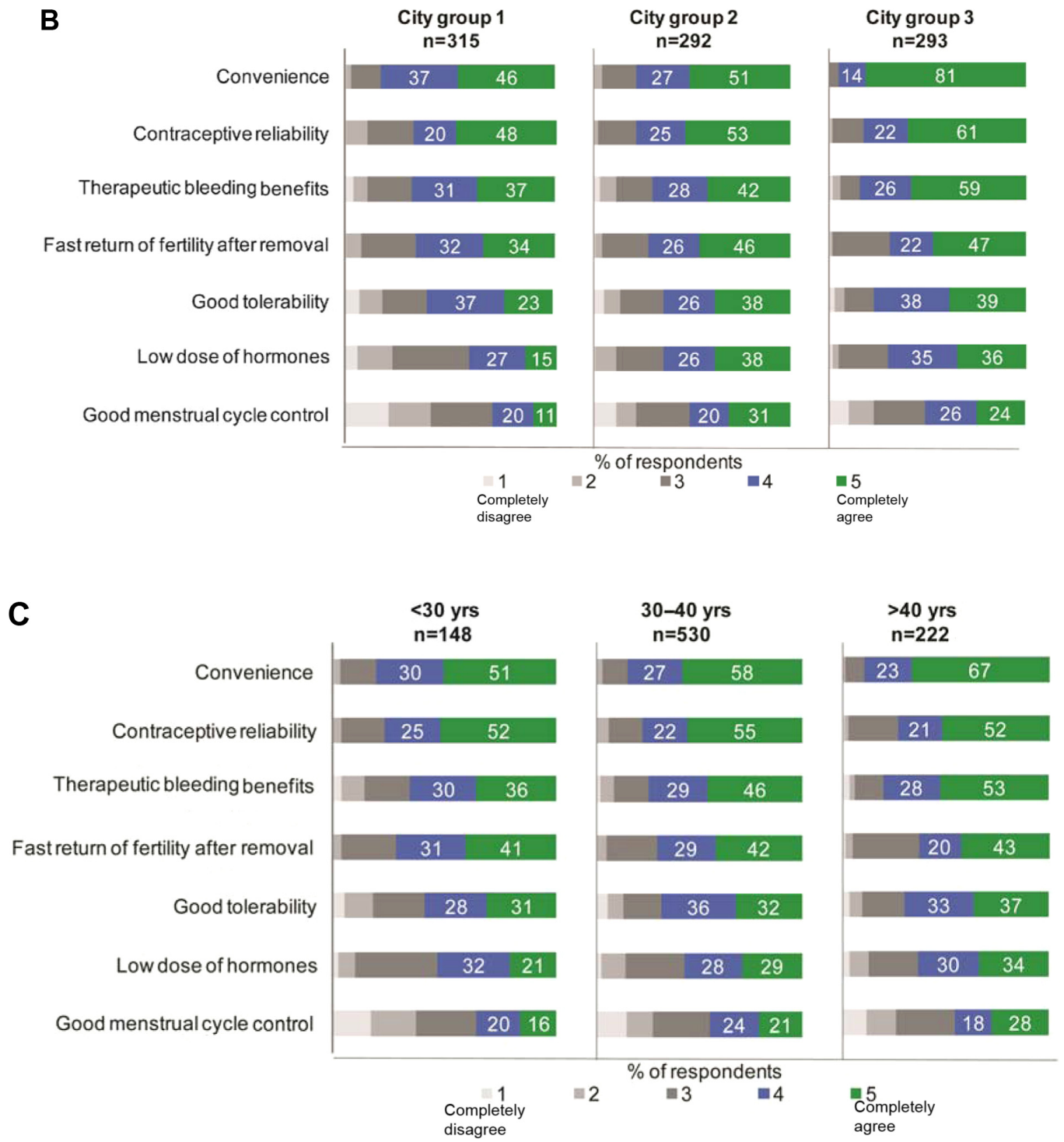

Figure 4 Agreement levels with the information provided on the attributes of Mirena ${ }^{\circledR}$ (Bayer Healthcare Pharmaceuticals, Whippany, NJ, USA). Notes: $(\mathbf{A})$ at the first and second follow-up visits, (B) by city group, and $(\mathbf{C})$ by respondent age. 


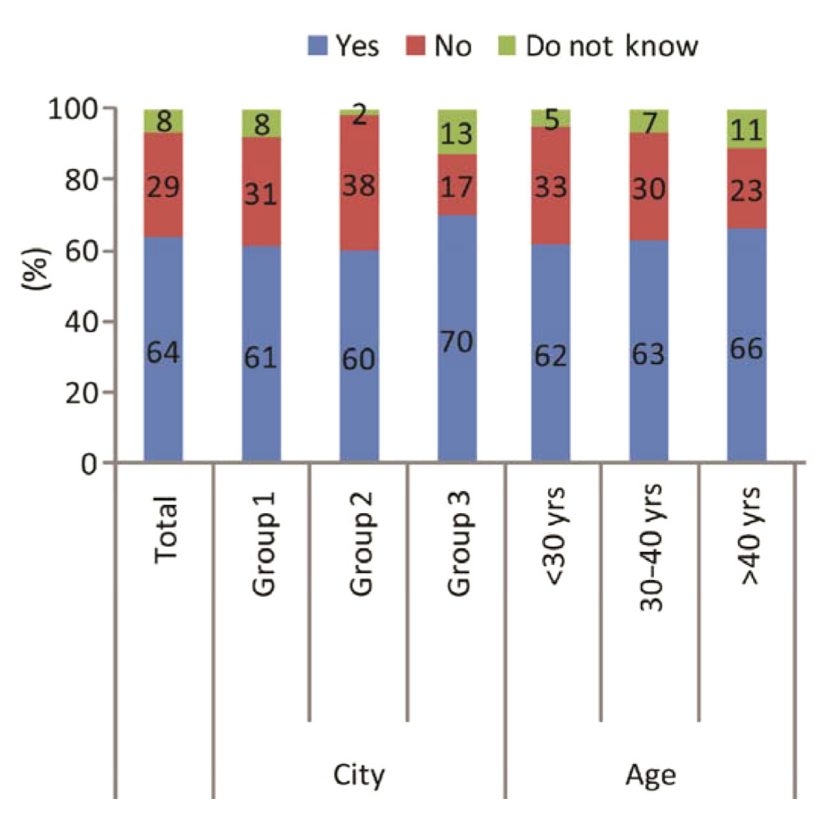

Figure 5 Percentages of respondents at the second follow-up visit who would recommend Mirena ${ }^{\circledR}$ (Bayer Healthcare Pharmaceuticals, Whippany, NJ, USA) to their friends.

information leaflet about Mirena that was provided for the preinsertion counseling, which may have influenced their responses to the questionnaires.

\section{Conclusion}

This survey shows that preinsertion counseling is very important for Chinese women contemplating use of Mirena, and that more and more health care providers are now paying attention to such counseling. The high level of agreement with the counseling information offered was reflected in the high continuation rate as well as the high levels of satisfaction among Mirena users. Overall, Mirena was well accepted by Chinese women.

\section{Acknowledgment}

Editorial assistance was provided by Content Ed Net, Shanghai Co Ltd.

\section{Disclosure}

Financial support for this study was provided by Bayer HealthCare China Ltd. Otherwise, the authors have no conflicts of interest to report in this work.

\section{References}

1. Kaunitz AM, Inki P. The levonorgestrel-releasing intrauterine system in heavy menstrual bleeding: a benefit-risk review. Drugs. 2012; $72: 193-215$.

2. Gemzell-Danielsson K, Schellschmidt I, Apter D. A randomized, phase II study describing the efficacy, bleeding profile, and safety of two low-dose levonorgestrel-releasing intrauterine contraceptive systems and Mirena. Fertil Steril. 2012;97:616-622.e1-e3.

3. Thonneau PF, Almont T. Contraceptive efficacy of intrauterine devices. Am J Obstet Gynecol. 2008;198:248-253.

4. Sonnenberg FA, Burkman RT, Hagerty CG, Speroff L, Speroff T Costs and net health effects of contraceptive methods. Contraception. 2004;69:447-459.

5. Römer T, Linsberger D. User satisfaction with a levonorgestrel-releasing intrauterine system (LNG-IUS): data from an international survey. Eur J Contracept Reprod Health Care. 2009;14:391-398.

6. Baldaszti E, Wimmer-Puchinger B, Löschke K. Acceptability of the long-term contraceptive levonorgestrel-releasing intrauterine system (Mirena): a 3-year follow-up visit study. Contraception. 2003; 67:87-91.

7. Backman T, Huhtala S, Blom T, Luoto R, Rauramo I, Koskenvuo M. Length of use and symptoms associated with premature removal of the levonorgestrel intrauterine system: a nation-wide study of 17,360 users. BJOG. 2000;107:335-339.

8. Suhonen S, Haukkamaa M, Jakobsson T, Rauramo I. Clinical performance of a levonorgestrel-releasing intrauterine system and oral contraceptives in young nulliparous women: a comparative study. Contraception. 2004;69:407-412.

9. Marions L, Lövkvist L, Taube A, Johansson M, Dalvik H, Øverlie I Use of the levonorgestrel releasing-intrauterine system in nulliparous women - a non-interventional study in Sweden. Eur J Contracept Reprod Health Care. 2011;16:126-134.

10. Prager S, Darney PD. The levonorgestrel intrauterine system in nulliparous women. Contraception. 2007;75(Suppl 6):S12-S15.

11. Jones RL, Critchley HO. Morphological and functional changes in human endometrium following intrauterine levonorgestrel delivery. Hum Reprod. 2000;15(Suppl 3):162-172.

\section{Publish your work in this journal}

Patient Preference and Adherence is an international, peer-reviewed, open access journal that focuses on the growing importance of patient preference and adherence throughout the therapeutic continuum. Patient satisfaction, acceptability, quality of life, compliance, persistence and their role in developing new therapeutic modalities and compounds to optimize

\section{Dovepress}

clinical outcomes for existing disease states are major areas of interest for the journal. This journal has been accepted for indexing on PubMed Central. The manuscript management system is completely online and includes a very quick and fair peer-review system, which is all easy to use. Visit http://www. dovepress.com/testimonials.php to read real quotes from published authors. 